Laser Chem., 1999, Vol. 19, pp. 187-190

Reprints available directly from the publisher Photocopying permitted by license only
(C) 1999 OPA (Overseas Publishers Association) N.V. Published by license under the Harwood Academic Publishers imprint, part of The Gordon and Breach Publishing Group.

\title{
TRANSIENT RAMAN SPECTROSCOPY OF ISOTOPE-SUBSTITUTED SPECIES OF BACTERIOCHLOROPHYLL $a$, BACTERIOPHEOPHYTIN $a$ AND CHLOROPHYLL a: CHANGES IN THE BOND ORDERS IN THE MACROCYCLES UPON TRIPLET AND SINGLET EXCITATION
}

\author{
YASUSHI KOYAMA*, LEENAWATY LIMANTARA \\ and TOKUTAKE SASHIMA
}

Faculty of Science, Kwansei Gakuin University, Uegahara, Nishinomiya 662, Japan

(Received 7 April 1997)

The $\mathrm{S}_{0}, \mathrm{~T}_{1}$ and $\mathrm{S}_{1}$ Raman spectra of bacteriochlorophyll $a$, bacteriopheophytin $a$ and chlorophyll $a$ were recorded for the species of natural abundance isotopic composition and those of totally substituted with ${ }^{15} \mathrm{~N},{ }^{13} \mathrm{C}$ and ${ }^{2} \mathrm{H}$ isotopes. Based on empirical assignments of the Raman lines, changes in the bond orders in the macrocycle upon triplet and singlet excitation are discussed.

Keywords: Raman; (bacterio)chlorophyll a; electronic excited states; bond orders

The excited-state structures of bacteriochlorophyll (BChl) $a$, bacterioäpheophytin (BPhe) $a$ and chlorophyll (Chl) $a$ play crucial roles in the primary processes in photosynthesis (see Fig.1 for the chemical structures of $\mathrm{BChl} a$ and $\mathrm{Chl} a$ ). The electronic orbitals and the molecular geometry of the conjugated macrocycles are supposed to be correlated closely with each other in each of the $S_{0}, T_{1}$ and $S_{1}$ states. In

\footnotetext{
* Corresponding author.
} 
(a)

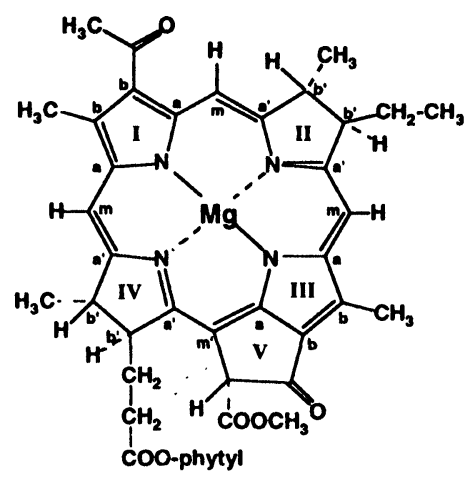

(b)

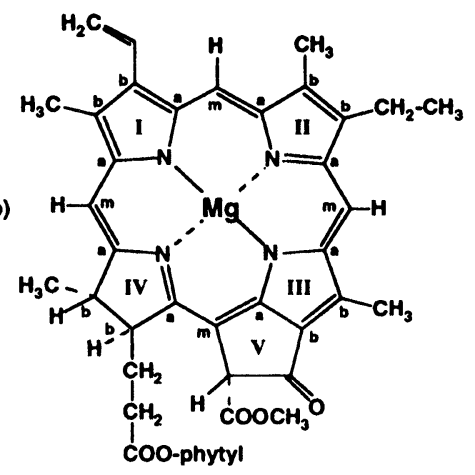

FIGURE 1 The chemical structures of (a) BChl $a$ and (b) Chl $a$.

particular, changes in the bond orders upon excitation of the macrocycles can be probed by transient resonance Raman spectroscopy as changes in the frequencies of the stretching Raman lines, when they are characterized by the use of isotope-shifts.

The Raman spectra of BChl $a$ and BPhe $a$ in acetone solution were recorded in the $S_{0}, T_{1}$ and $S_{1}$ states by the use of the CW $457.9 \mathrm{~nm}$ beam, the $420 \mathrm{~nm} \sim 5 \mathrm{~ns}$ pulses, and the $351 \mathrm{~nm} \sim 50 \mathrm{ps}$ pulses, respectively. One-color pump-and-probe methods were used to obtain the $\mathrm{T}_{1}$ and $\mathrm{S}_{1}$ Raman spectra; the difference spectrum of high photondensity spectrum minus low photon-density spectrum was taken in each case. The Raman lines were characterized empirically by the use of isotope shifts upon full ${ }^{15} \mathrm{~N},{ }^{13} \mathrm{C}$ and ${ }^{2} \mathrm{H}$ substitutions, and the shifts of the characterized Raman lines upon excitation to the $T_{1}$ and $S_{1}$ states were correlated with changes in the bond orders in the macrocycles. Figure 2 compares schematically the Raman lines of BChl $a$ in the (a) $\mathrm{S}_{0}$, (b) $\mathrm{T}_{1}$ and (c) $\mathrm{S}_{1}$ states. Spectral comparison reveals the following systematic changes in bond order in the order, the $\mathrm{S}_{0}, \mathrm{~T}_{1}$ and then $\mathrm{S}_{1}$ state: the $\mathrm{C}_{a^{\prime}}-\mathrm{C}_{m}$ bond having a double-bond character decreases in bond order, whereas the $\mathrm{C}_{a}-\mathrm{N}$ bond having a single-bond character increases in the bond order. Comparison of the Raman lines of BPhe $a$ in the $\mathrm{S}_{0}, \mathrm{~T}_{1}$ and $\mathrm{S}_{1}$ states has revealed that similar changes in the $\mathrm{C}_{a^{\prime}}-\mathrm{C}_{m}$ and $\mathrm{C}_{a}-\mathrm{N}$ bond orders take place upon triplet excitation, although changes in these bond orders upon singlet excitation are more complicated (data not shown) [1]. 

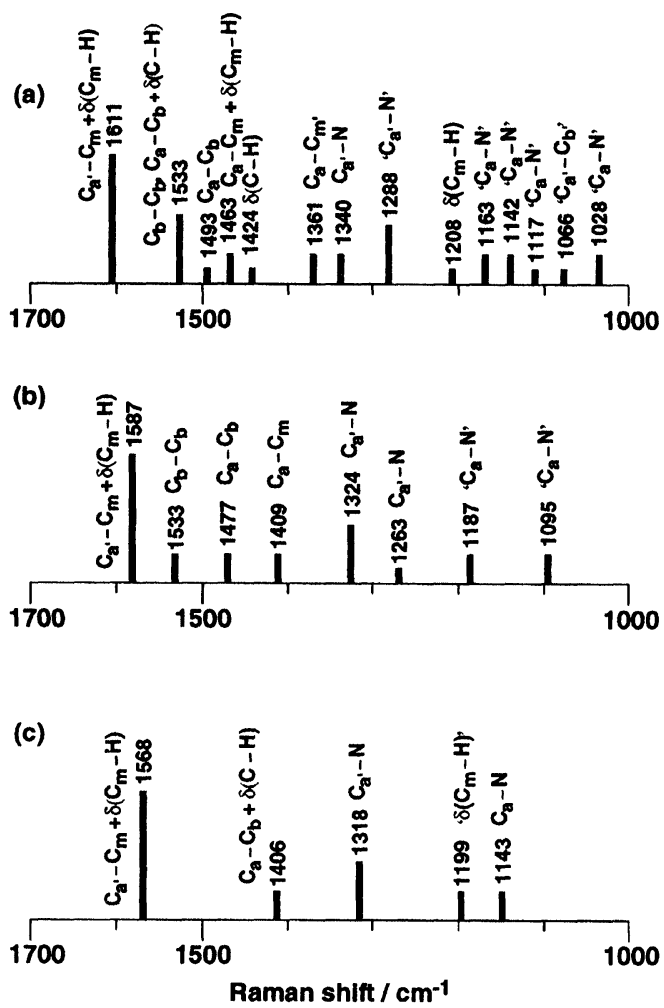

FIGURE 2 Schematic presentation of the characterized Raman lines of $\mathrm{BChl} a$ in the (a) $S_{0}$, (b) $T_{1}$ and (c) $S_{1}$ states.

The $\mathrm{S}_{0}$ Raman spectrum of Chl $a$ was recorded in ethanol by the use of the 457.9-nm beam; the $T_{1}$ Raman spectrum was recorded in ethanol by a two-color method using the 436-nm pump and 457.9-nm probe pulses (the two color method was necessary to detect selectively the relaxed $T_{1}$ state); and the $S_{1}$ Raman spectrum was recorded in benzene (the $S_{1}$ measurement was hampered by strong fluorescence in ethanol). The Chl $a$ species with different isotopic compositions, i.e., $\mathrm{NA},{ }^{15} \mathrm{~N} ;{ }^{13} \mathrm{C},{ }^{13} \mathrm{C} \&{ }^{15} \mathrm{~N}$; and ${ }^{2} \mathrm{H},{ }^{2} \mathrm{H} \&{ }^{15} \mathrm{~N}$, were used to facilitate empirical assignments of the Raman lines using shifts upon ${ }^{15} \mathrm{~N}$ substitutions. A preliminary normal-coordinate analysis was also performed to assign the $S_{0}$ Raman lines. Figure 3 lists the $S_{0}, T_{1}$ and $S_{1}$ Raman lines of NA Chl $a$, which are associated with the $\mathrm{C}_{a}-\mathrm{C}_{m}$ 

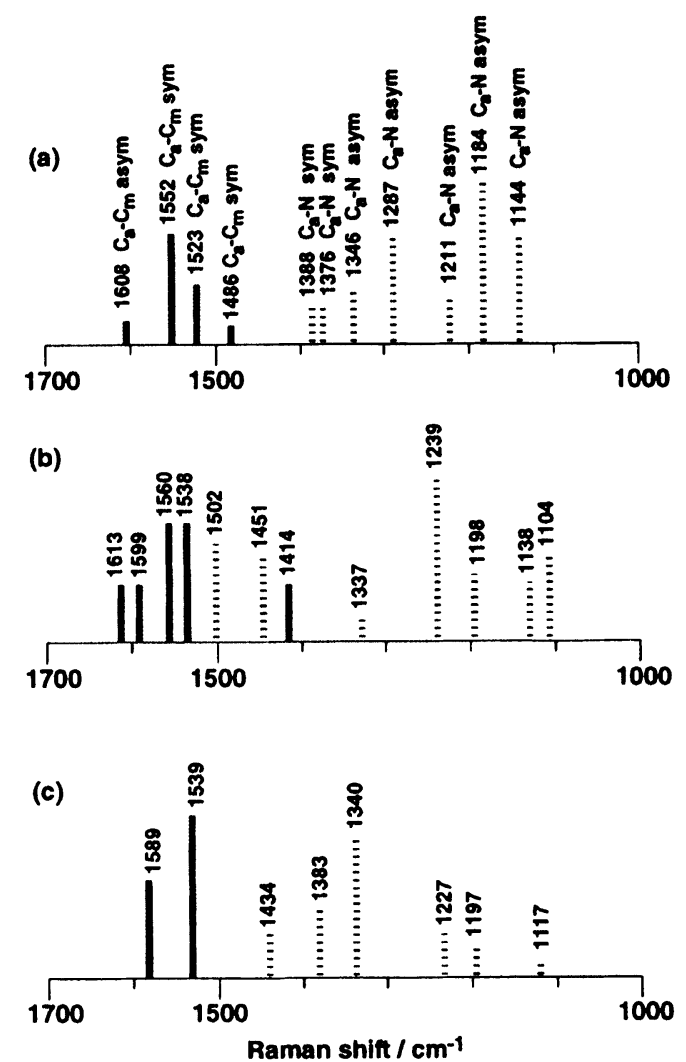

FIGURE 3 Schematic presentation of the Raman lines of Chl $a$ associated with the $\mathrm{C}_{a}-\mathrm{C}_{m}$ stretchings or the $\mathrm{C}_{a}-\mathrm{N}$ stretchings in the (a) $\mathrm{S}_{0}$, (b) $\mathrm{T}_{1}$ and (c) $\mathrm{S}_{1}$ states.

stretchings (hard lines) or the $\mathrm{C}_{a}-\mathrm{N}$ stretchings (broken lines). The results indicate that the bond orders are changed drastically upon triplet excitation, and that they are changed little upon singlet excitation [2].

\section{References}

[1] Koyama, Y. and Limantara, L. (1998). Spectrochim. Acta Part A, 54, 1127-1139.

[2] Sashima, T., Abe, M. Kurano, N. Miyachi, S. and Koyama, Y., J. Phys. Chem., in press. 